\title{
Epidemiological Profile of Drug Overdose Reported in South-East Morocco from 2004 to 2016
}

\author{
Karima Azekour ${ }^{1} \cdot$ Souad Belamalem ${ }^{2} \cdot$ Abdelmajid Soulaymani $^{2} \cdot$ Brahim El Houate $^{3} \cdot$ Bachir El Bouhali $^{1}$ (D)
}

Published online: 28 February 2019

(c) The Author(s) 2019

\begin{abstract}
Background Drug overdose, either accidental or intentional, is the most common cause of acute poisoning worldwide. Objective The aim of this study was to determine the epidemiological profile of drug poisoning recorded in the south east of Morocco and to identify the proportion of intentional versus accidental drug overdose.

Methods This was an epidemiological study of 180 cases of medicinal poisoning registered with the Provincial Delegation of Health in Errachidia between January 2004 and December 2016. Information on demographic and drug overdose characteristics was obtained from the regional poison center. Drugs were categorized according to the anatomical therapeutic chemical (ATC) classification system.

Results Adults were the most affected group, with a median age of 21 years and a sex ratio of three females to every male. Drug poisoning mainly occurred in urban areas (83\% of cases). Regarding clinical signs, $55.2 \%$ of patients presented with digestive signs and $27.6 \%$ with neurological signs. Other signs were also present: respiratory (5.1\%), combined neurological and digestive (4.5\%), cardiovascular (3.8\%), and general (3.8\%). Women represented $88.9 \%$ of those who had intentionally overdosed and $64.3 \%$ of those who had unintentionally overdosed. Benzodiazepine derivatives and other related drugs were involved in $21.5 \%$ of cases of drug poisoning, with other drugs found in patients with drug overdose as follows: paracetamol $3.3 \%$, ethinyl estradiol/levonorgestrel $5 \%$, and cyproheptadine $1.6 \%$.

Conclusion Our results indicate that the number of reported cases of drug poisoning in south-east Morocco increased between 2004 and 2016. The intentional use of drugs in overdose was mostly among adults, especially women. The drugs involved were predominantly psycholeptic drugs, followed by analgesics. Mortality was low, but investigation in a representative sample will show the real severity and outcomes of drug overdoses.
\end{abstract}

\section{Key Points}

Cases of intentional drug overdoses reported in south-east Morocco increased each year between 2004 and 2016.

Young- to middle-aged women were more frequently involved than men in both intentional and accidental drug overdoses.

Psycholeptic drugs were the most frequently involved drugs.

Bachir El Bouhali

bachirbouhali@hotmail.com

1 Department of Biology, Faculty of Science and Techniques, University Moulay Ismail, BP509, 52000 Errachidia, Morocco

2 Department of Biology, Faculty of Science, Kenitra, Morocco

\section{Introduction}

Drug poisoning (drug overdose) is the accidental or intentional ingestion of sufficient drug or drugs to cause injury or death. This type of poisoning presents a significant risk to human health and a real emergency and resuscitation problem in many countries [1].

In 2004, the World Health Organization reported 345,814 cases of death by poisoning worldwide, or 5.4 deaths per 100,000 inhabitants [2]. The incidence of drug poisoning has increased regularly in the last 30 years,

\footnotetext{
Higher Institute of Nursing and Health Techniques Professions, Ouarzazate, Morocco
} 
rising from $1-1.5$ to $5-6$ poisonings per 1000 inhabitants in 1970 and 1990, respectively.

The incidence of drug overdoses has increased in several countries over the past decade. Many suicide cases were the result of drug poisoning in England and Wales between 1993 and 1999 [3]. The USA is experiencing an epidemic of deaths attributable to drug overdose, with the rate of these deaths increasing by $137 \%$ since $2000[4,5]$. Drugs continue to be the primary cause of acute intoxication in France [6].

Morocco is one such country concerned by this public health problem. Drug poisoning accounts for $23 \%$ of all poisoning, second only to venomous poisoning, and nearly $52 \%$ of cases are intentional $[7,8]$. Some national studies on poisonings have been conducted but have focused on all substances with a significant potential to cause harm [7-11]. No study has been undertaken in south-east Morocco to specifically describe cases of drug overdose. Health professionals have noted that the use of medicinal drugs in intentional poisoning has become increasingly common in this region and has not received due attention. A description of drug poisoning cases is needed.

This study aimed to describe the profile of patients involved in drug overdosing, quantify the proportion of intentional drug overdosing, and identify the most frequently involved drug classes over a period of 12 years in the region of Errachidia.

\section{Material and Methods}

\subsection{Location}

This was an epidemiological study of cases of drug poisoning recorded between 2004 and 2016 in health services in Errachidia, a semi-urban region situated in south-east Morocco. It is considered one of the most historically important regions of Morocco, with little industrial development but an important tourism sector. The 2014 census reported that the population in this province numbers 418,451 inhabitants, including more than 224,317 in rural areas. The population comprises a mixture of many ethnic groups, such as Arabs and Amazighs.

\subsection{Data Source}

The data used for this study were derived from anonymized medical declaration records of drug overdose completed by doctors or nurses. In Morocco's emergency service, such a declaration form must be completed for each patient admitted to hospital because of poisoning. These declarations, from any health service in the region, are centralized at the service of health facility networks. We collected and analyzed all cases of medicinal drug overdose in the region and excluded cases involving other poisoning agents (chemicals, plants, and other toxic substances). The Health Provincial Delegation of Errachidia provided authorization to conduct the research.

\subsection{Clinical and Demographic Characteristics}

Our methodology is based on a description of the sample. Data were recorded and analyzed in Microsoft Excel. The study concerned the frequency of drug overdose, evolution over time, sociodemographic parameters (age, sex, origin), specificities of intoxication (method, place, circumstances), clinicalQuery presentations, and patient outcomes. We conducted a descriptive analysis of all variables, with quantitative variables expressed as mean, frequency, and percentage. Patient characteristics according to intentional or accidental overdoses were analysed using the $\chi^{2}$ test, and $p$ values $<0.05$ were considered statistically significant for all comparisons.

\section{Results}

\subsection{Profile of Patients with Drug Overdose}

Table 1 shows the distribution of drug overdose cases according to the epidemiological characteristics of the studied population.

Between 2004 and 2016, a total of 180 cases of drug poisoning were reported in the Provincial Delegation of Health in Errachidia, with an average rate of $14 \pm 2.7$ cases per year (range 2-40). The number of reported drug overdoses increased markedly between 2014 and 2016 (Fig. 1).

In the area chosen for our study, the ages of patients with drug poisoning ranged from 2 to 75 years, with a median age of 21 years. Poisoning by drugs affected all age groups but predominantly adult patients (54.4\%), followed by adolescents $(27.8 \%$ ) (Table 1$)$.

The majority $(82.8 \%)$ of drug poisoning cases were from urban areas. Drug poisoning was accidental in 101 cases $(56.1 \%)$ and intentional in 72 cases $(40 \%)$; intent was undetermined for seven cases (3.9\%) (Table 1). In total, 96.1\% of all drug overdose cases occurred at home. Females were the most affected ( 75 vs. $25 \%$ for males), with a sex ratio of three females to one male. Figure 2 shows a persistent and significant predominance of women in both those treated for intentional drug poisoning (91.7\%) and in those who unintentionally overdosed (64.3\%). 
Table 1 Patient characteristics according to intentional or accidental overdose

\begin{tabular}{|c|c|c|c|c|c|}
\hline Variables & $\begin{array}{l}\text { Patients, } N=180 \text {, } \\
n(\%)\end{array}$ & $\begin{array}{l}\text { Accidental, } \\
n=101\end{array}$ & $\begin{array}{l}\text { Intentional, } \\
n=72\end{array}$ & $\chi^{2}$ & $p$ value \\
\hline Age groups, years (median) & & & & 29.797 & 0.001 \\
\hline Toddler (2.5) & $16(8.9)$ & 16 & 0 & & \\
\hline Child (9.5) & $12(6.7)$ & 10 & 1 & & \\
\hline Adolescent (17) & $50(27.8)$ & 16 & 32 & & \\
\hline Adults (47) & $98(54.4)$ & 57 & 37 & & \\
\hline Elderly $(\geq 74)$ & $1(0.5)$ & 1 & 0 & & \\
\hline Unknown & $3(1.7)$ & 1 & 2 & & \\
\hline Origin & & & & 4.906 & 0.297 \\
\hline Rural & $28(15.5)$ & 12 & 14 & & \\
\hline Urban & $149(82.8)$ & 86 & 58 & & \\
\hline Unknown & $3(1.7)$ & 3 & 0 & & \\
\hline Place of poisoning & & & & 16.195 & 0.003 \\
\hline Home & $173(96.1)$ & 98 & 70 & & \\
\hline Job & $1(0.5)$ & 0 & 1 & & \\
\hline Unknown & $6(3.4)$ & 3 & 1 & & \\
\hline Clinical status & & & & 27.607 & 0.000 \\
\hline Conscious & $104(57.8)$ & 70 & 30 & & \\
\hline Comatose & $12(6.7)$ & 1 & 11 & & \\
\hline Dizzy & 34 (18.9) & 14 & 20 & & \\
\hline Unknown & $30(16.6)$ & 16 & 11 & & \\
\hline Hospitalized & & & & 29.090 & 0.000 \\
\hline Yes & $132(73.3)$ & 60 & 65 & & \\
\hline No & $44(24.5)$ & 38 & 6 & & \\
\hline Unknown & $4(2.3)$ & 3 & 1 & & \\
\hline Treatment & & & & 14.035 & 0.081 \\
\hline No specific treatment & $5(2.8)$ & 3 & 2 & & \\
\hline Purifier treatment & $1(0.5)$ & 0 & 1 & & \\
\hline Evacuator treatment & $45(25)$ & 17 & 27 & & \\
\hline Symptomatic treatment & $86(47.8)$ & 51 & 30 & & \\
\hline Unknown & 43 (23.9) & 30 & 12 & & \\
\hline
\end{tabular}

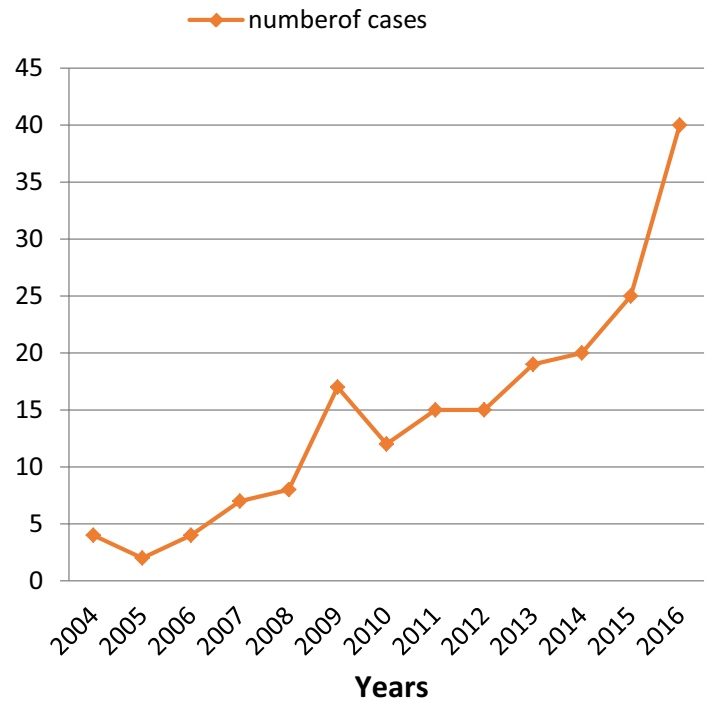

Fig. 1 Distribution of drug poisoning by years

\subsection{Clinical Characteristics}

Table 1 shows the distribution of clinical signs and symptoms during drug intoxication in the region of Errachidia. Most patients with accidental drug overdose were conscious when admitted to the emergency service, whereas more patients were comatose when admitted after intentional overdose, which explains the high rate of hospitalization among these patients (Table 1).

Signs in the clinical picture were primarily digestive (55.2\%), followed by neurological (27.6\%) and respiratory (12.2\%) signs. Other signs were also present: combination of neurological and digestive signs $(4.5 \%)$, cardiovascular signs (3.8\%), and general signs (3.8\%) (Fig. 3).

Patient outcomes after treatment were favorable for $98.3 \%$ of cases, whereas $1.7 \%$ of patients died. Patients with symptoms were treated symptomatically in $47.8 \%$ of cases. The aim of this type of treatment is to immediately 


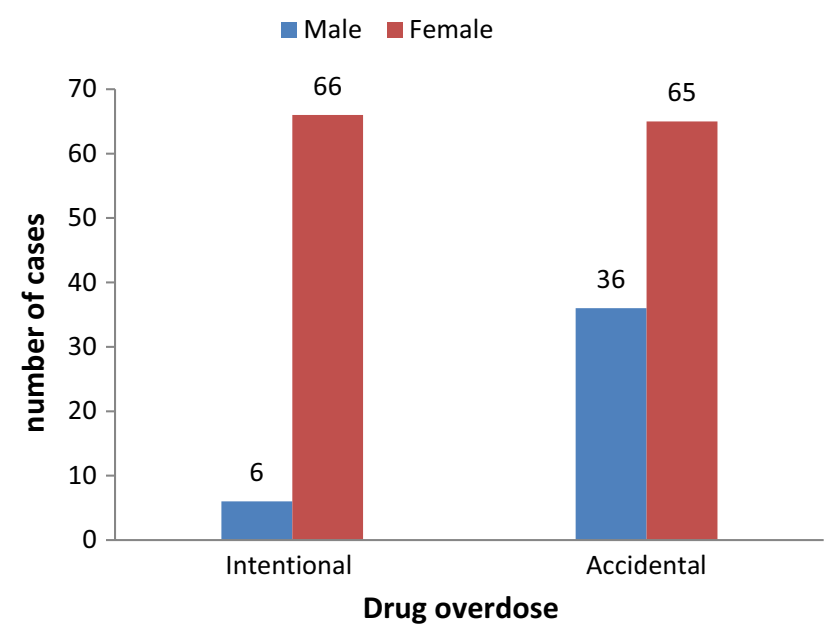

Fig. 2 Distribution of patients engaging in drug overdose according to sex

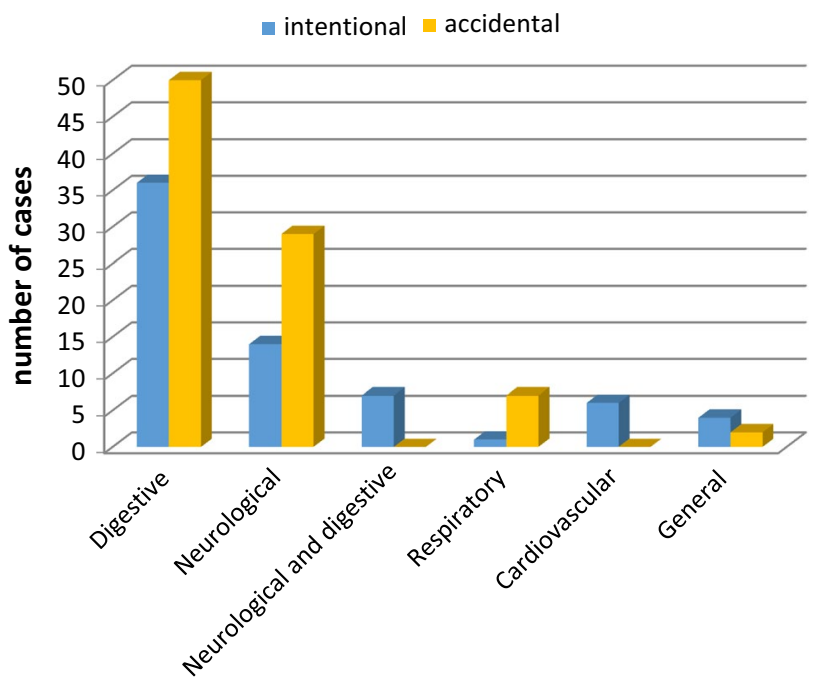

Fig. 3 Distribution of clinical signs in patients engaging in drug overdose

correct a vital failure to restore or preserve homeostasis of the inner environment. Good symptomatic treatment is often sufficient to ensure a favorable outcome in many poisonings. A total of $25 \%$ of cases underwent evacuator treatment to decrease absorption of the toxic substance and the potential severity of the poisoning. Purifier treatments were applied in $0.5 \%$ and no specific treatment was administered for $2.8 \%$. Information on the treatment used was not provided for $23.9 \%$ of patients.

\subsection{Drug Involved}

In total, 180 records indicated the nature of the drug taken, which were classified according to the first level of the anatomical therapeutic chemical (ATC) classification. As shown in Table 2, among these 180 records, the main drugs used in intentional and accidental drug poisoning were nervous system drugs, followed by drugs and medicines relating to the genitourinary system, sex hormones, and the respiratory system. The most frequently used drugs were psycholeptic drugs (N05) (alprazolam, chlorpromazine, bromazepam, prazepam, and bromazepam), which were cumulatively involved in $21.5 \%$ of cases. Paracetamol was involved in $3.3 \%$ of drug overdoses. Antiparkinson drugs (N04), psychoanaleptics (N06), and antiepileptics (N03) were also frequently used in drug overdoses. At 5\% of reported cases, ethinyl estradiol/levonorgestrel were the primary drugs related to the genitourinary system and sex hormones. Cyproheptadine, an antihistamine for systemic use, was used in $1.6 \%$ of reported cases.

\section{Discussion}

The current study describes the clinical and epidemiological characteristics of accidental and intentional drug poisoning reported in the south east of Morocco. Over the period 2004-2016, the number of drug poisoning cases reported in the provincial delegation of health in Errachidia increased year on year, which is similar to results described in other regions of the country [8-11]. Drug poisoning is the primary cause of poisoning in the oriental (north Morocco) and Marrakech-Tensift-Al Haouz (central Morocco) regions [9, 11]. The increasing menace of drug poisoning is alarming. Data from the Anti-Poison and Pharmacovigilance Center of Morocco indicate that medicinal poisoning occupies second place after food poisoning and excluding venomous poisoning $[9,10]$, which can be attributed to the availability and growing use of drugs within the population because of improved medical coverage and health insurance. Despite continuous efforts by the Ministry of Health to improve surveillance systems, the number of patients with intentional or accidental drug overdose remains underestimated, and cases are still under-diagnosed and/or under-notified.

\subsection{Drug Overdose and Demographic Characteristics}

Similar to findings from other studies [9, 12], our data analysis found that adults and adolescents were most represented in drug poisoning (median age 21 years). We found a predominance of females in the total number of drug overdoses, similar to findings in other countries [6,12-15]. We identified that a high proportion (91.1\%) of intentional poisoning cases involved females, which contrasts with a frequency of $52.3 \%$ reported in a national study [8]. Many studies [12-14, 
Table 2 Drugs most implicated in overdoses

\begin{tabular}{lllc}
\hline Drug class (ATC) & Drug & Code & $N=180, n(\%)$ \\
\hline Nervous system & Alprazolam & N05BA12 & $15(8.3)$ \\
& Carbamazepine & N03AF01 & $9(5)$ \\
& Chlorpromazine & N05AA01 & $9(5)$ \\
& Trihexyphenidyl hydrochloride & N04AA01 & $6(3.3)$ \\
& Amitriptyline & N06AA09 & $6(3.3)$ \\
& Bromazepam & N05BA08 & $6(3.3)$ \\
& Lamotrigine & N03AX09 & $6(3.3)$ \\
& Paracetamol & N02BE01 & $6(3.3)$ \\
& Prazepam & N05BA11 & $6(3.3)$ \\
& Valproic acid & N03AG01 & $6(3.3)$ \\
& Bromazepam & N05BA08 & $3(1.6)$ \\
Genitourinary system and & Ethinyl estradiol/levonorgestrel & N03AA02 & $3(1.6)$ \\
Rex hormones & G03AA07 & $9(5)$ \\
\hline & Cyproheptadine & & $3(1.6)$ \\
\hline
\end{tabular}

$A T C$ anatomical therapeutic chemical classification
16] have reported that drugs are being used in deliberate self-harming and in suicide attempts. Previous national studies found a transition in products used in acute poisoning, whereby drugs are increasingly being used in suicide attempts instead of the more traditional products such as paraphenylenediamine and toxic plants $[7,8]$. This could be because the drugs are easy to obtain and consume and because of the general ignorance about the damage to be expected with higher doses of drugs.

Our findings about the location of drug poisoning indicated it occurred more often in urban areas, which is in alignment with other studies [7, 8, 16, 17], but the frequency of overdose in rural areas is not negligible (40\%). This distribution is likely because the majority of the rural population use traditional medications, so pharmaceutic drugs are less present and even avoided.

\subsection{Drugs Involved}

Our findings show that psycholeptic drugs predominate in overdoses, followed by analgesics, a pattern that differs from that in most western countries, where neuropsychiatric drugs are in second place. Benzodiazepines are the primary neuropsychiatric drug class involved in many poisoning cases [17, 18]. It should be noted that, in Morocco, patients require a prescription and a certified copy of their identification document to access most of these drugs. The increased prescription of psychotropic drugs and their illegal sale in the contraband market may increase their misuse. As described in some studies, other factors may also explain the involvement of these neuropsychiatric drug classes, particularly psychiatric illness and socioeconomic disadvantage $[8,10,19]$.
Interestingly, our results indicated another drug classoral analgesics-was also involved in drug overdoses (Table 2). These drugs have few adverse effects at the recommended dose, but the level of drug overdose by analgesics reported in our study is not surprising as paracetamol (acetaminophen) is the most common drug used for selfpoisoning in many countries. In Morocco, paracetamol can be purchased at a pharmacy without a prescription. As in other countries, a high percentage of analgesics and nonsteroidal anti-inflammatory drugs are used in drug overdoses [14, 20].

Another underestimated drug class is exogenous estrogen. High doses of contraceptive pills may induce some serious clinical signs, including pulmonary thromboembolism and cerebrovascular accidents [21-23]. Overdoses involving oral contraceptive pills are expected to increase in our country, because of the availability of the drugs. Contraceptive pills are the most used contraceptive method in Morocco, and many women use them without any medical advice.

Cyproheptadine is the most used respiratory system drug, accounting for nearly $5 \%$ of pharmacy sales in Morocco [24]. Some women in Morocco misuse this drug to gain weight, which may explain the frequent involvement of these drugs in overdoses [8, 25].

\section{Limitations and Perspectives}

Our study includes a number of limitations. Our findings may underestimate the real drug overdose situation in this region. We recognize there is incomplete reporting of information on case numbers and the description of some characteristics 
related to drug overdose. Health personnel are subject to reporting bias, and clinical effects and medical outcomes recorded were limited to a general description at the organ and system level. We do not know whether some individuals were represented by multiple exposures. Finally, the main limitation is the small sample size, which may have inherent biases that may affect our results.

Our study opens the way for more investigation into the characterization of drug poisoning phenomena. Some aspects that may be considered to focus future efforts:

- the use of drugs as a method of poisoning is increasing in this region

- more effort should be made to control prescription drugs, and guidelines should be used in the prescription of anxiolytic and analgesic drugs

- cultural and personality factors should be carefully considered because they may be responsible for some specific behaviors in drug overdose $t$.

\section{Conclusion}

Drug poisoning remains underestimated but is increasing in number in the south east of Morocco. Women are a major risk group for intentional and accidental drug poisoning. Multiple drugs are used by individuals affected by drug overdose. The drug classes primarily involved in overdoses in this study were those acting on the nervous, genitourinary, and respiratory systems and sex hormones. More focus on and characterization of affected patients is needed to address the growing overdose problem in the south east of Morocco.

Author Contributions KA conducted the research and analyzed the data and is the primary author of this work. BB supervised the study. $\mathrm{BE}, \mathrm{SB}$, and AS provided input to the analyses and the manuscript. All authors read and approved the final manuscript.

\section{Compliance with Ethical Standards}

Funding No sources of funding were used to conduct this study or prepare this manuscript.

Conflict of interest KA, SB, AS, BE, and BB have no conflicts of interest that are directly relevant to the content of this article.

Open Access This article is distributed under the terms of the Creative Commons Attribution-NonCommercial 4.0 International License (http://creativecommons.org/licenses/by-nc/4.0/), which permits any noncommercial use, distribution, and reproduction in any medium, provided you give appropriate credit to the original author(s) and the source, provide a link to the Creative Commons license, and indicate if changes were made.

\section{References}

1. Slavova S, Bunn TL, Talbert J. Drug overdose surveillance using hospital discharge data. Public Health Rep. 2014;129(5):437-45. https://doi.org/10.1177/003335491412900507.

2. The global burden of disease: 2004 update. Geneva, World Health Organization, 2008.

3. Shah R, Uren Z, Baker A, Majeed A. Trends in suicide from drug overdose in the elderly in England and Wales, 1993-1999. Int J Geriatr Psychiatry. 2002;17(5):416-21. https://doi.org/10.1002/ gps.625.

4. Rudd A, Aleshire N, Zibbell JE, Gladden RM. Increases in drug and opioid overdose deaths-United States, 2000-2014. Am J Transplant. 2016;16:1323-7. https://doi.org/10.1111/ajt.13776.

5. Rudd RA, Aleshire N, Zibbell JE, Gladden RM. Increases in drug and opioid overdose deaths-United States, 2000-2014. MMWR Morb Mortal Wkly Rep. 2016;64(50):1378-82. https://doi. org/10.15585/mmwr.mm6450a3.

6. Adnet F, Atout S, Galinski M, Lapostolle F. Changing pattern of drug poisonings in France. Réanimation. 2005;14(8):721-6. https ://doi.org/10.1016/j.reaurg.2005.10.023.

7. Mahir S, Soulaymani A, Hami H, Mokhtari A, Benali D, Ouammi $\mathrm{L}$, et al. Suicide by poisoning in the Souss-Massa-Draa region of Morocco. Sante Publique. 2013;25(3):343-50.

8. Ministry of Health. Official publication of the Anti Poison Center Morocco. Intoxications médicamenteuses au Maroc Données du Centre Anti Poison du Maroc (1980-2008). 2010.

9. Echahbi N, Soulaymani A, Hami H, Benazzouz B, Ouammi L, Mokhtari A, et al. Description of poisoning reported in Marrakech-Tensift-Al Haouz region in Morocco between 1981 and 2008. Bull Soc Pathol Exot. 2013;106(1):48-53. https://doi. org/10.1007/s13149-012-0210-8.

10. Attazagharti N, Soulaymani A, Ouami A, Mokhtari B, Soulaymani R. Intoxications médicamenteuses et facteurs de risque influençant l'évolution des patients. Antropo. 2009;19:33-9.

11. Rebgui H, Hami H, Ouammi L, Hadrya F, Soulaymani A, Soulaymani-Bencheikh $\mathrm{R}$ et al. Caractéristiques socioépidémiologiques et évolutives des intoxications aiguës au Maroc: cas de la région de l'oriental. Eur Sci J 2013;9.

12. Ichikura K, Okumura Y, Takeuchi T. Associations of adverse clinical course and ingested substances among patients with deliberate drug poisoning: a cohort study from an intensive care unit in Japan. PLoS One. 2016;11(8):e0161996. https://doi.org/10.1371/ journal.pone.0161996.

13. Edwards IR. Adverse drug effects and their clinical management: a personal view. Drug Saf. 2014;37(6):383-90. https://doi. org/10.1007/s40264-014-0167-6.

14. Camidge DR, Wood RJ, Bateman DN. The epidemiology of selfpoisoning in the UK. Br J Clin Pharmacol. 2003;56:613-9. https ://doi.org/10.1046/j.1365-2125.2003.01910.x.

15. Burillo-Putze G, Munne P, Duenas A, Pinillos MA, Naveiro JM, Cobo J, et al. National multicentre study of acute intoxication in emergency departments of Spain. Eur J Emerg Med. 2003;10(2):101-4. https://doi.org/10.1097/01.mej.0000072640 $.95490 .5 \mathrm{f}$.

16. Mekaoui N, Karboubi L, Ouadghiri FZ, Dakhama BS. Epidemiological aspects of suicide attempts among Moroccan children. Pan Afr Med J. 2016;24:112. https://doi.org/10.11604/ pamj.2016.24.112.7805.

17. Martins SS, Sampson L, Cerdá M, Galea S. Worldwide prevalence and trends in unintentional drug overdose: a systematic review of the literature. Am J Public Health. 2015;105(11):e29-49. https:// doi.org/10.2105/ajph.2015.302843.

18. Isbister GK, O'Regan L, Sibbritt D, Whyte IM. Alprazolam is relatively more toxic than other benzodiazepines in overdose. 
Br J Clin Pharmacol. 2004;58(1):88-95. https://doi.org/10.111 1/j.1365-2125.2004.02089.x.

19. Skegg K. Self-harm. Lancet. 2005;366(9495):1471-83.

20. Benlamkaddem S, Iken I, Houari N, Elbouazzaoui A, Boukatta $\mathrm{B}$, Sbai $\mathrm{H}$, et al. Paracetamol self-poisoning: when oral $N$-acetylcysteine saves life? A case report. Pan Afr Med J. 2018;29:83. https://doi.org/10.11604/pamj.2018.29.83.10595.

21. Celik C, Carus M, Buyukcam F. Pulmonary embolism due to exogenous estrogen intoxication. Am J Emerg Med. 2017;35(12):1984. e1. https://doi.org/10.1016/j.ajem.2017.07.084.

22. Weerasinghe M, Konradsen F, Eddleston M, Pearson M, Agampodi T, Storm F, Agampodi S. Overdose of oral contraceptive pills as a means of intentional self-poisoning amongst young women in Sri Lanka: considerations for family planning. J Fam Plann Reprod Health Care. 2017;43(2):147-50. https://doi.org/10.1136/jfprhc-2015-101171.

23. Sanchez-Ojanguren J, Escudero D, Zapata A. Occlusion of the right carotid artery due to oral estrogen overdose. Rev Neurol. 1998;27:604-6.

24. Taoufiq J, ElOmari F, Sabir M. 2014 Annual report of the National Observatory on drugs and addiction. Morocco. 2015.

25. Arraghraghi N. Misuse of cyproheptadine and corticosteroids in Morocco. Doctoral Dissertation. 2017. 